\title{
The Effect of Laser Therapy Along With Mediterranean Diet Versus Mediterranean Diet Only on Older Adults With Non-alcoholic Fatty Liver Disease: A Randomized Clinical Trial
}

\author{
Ebtesam Nabil Nagy ${ }^{1 *}$, Faten Mohamed Ibrahim ${ }^{2}$, Amal Abdelfattah Jouda ${ }^{3}$, Marwa Mahmoud Elsayed ${ }^{1}$ \\ 'Physical Therapy for Cardiovascular/Respiratory Disorder and Geriatrics Dept., Faculty of Physical Therapy, Cairo \\ University, 7 Ahmed El zyat St., Dokki,Giza, Egypt \\ ${ }^{2}$ Medicinal and Aromatic Plants Research Dept., National Research Center, 33 El Bohouth St., Dokki, Giza, Egypt \\ ${ }^{3}$ Tropical Medicine Dept., Faculty of Medicine, Zagazig University, University St., Zagazig, Sharkia, Egypt
}

\section{*Correspondence to \\ Ebtesam Nabil Nagy, Physical Therapy for Cardiovascular/ Respiratory Disorder and Geriatrics Dept., Faculty of Physical Therapy, Cairo University, 7 Ahmed El zyat St., Dokki,Giza, Egypt. P.O.11432. Tel: 0201278141946; Email: dr.Ebtesamnagy@outlook. com}

Received: November 8, 2020 Accepted: March 3, 2021 Published online July 24, 2021

\begin{abstract}
Introduction: Obesity is the major pathogenesis of the non-alcoholic fatty liver disease (NAFLD) The combination of low-level laser therapy (LLLT) and Mediterranean diet (MD) is a new approach for improving liver function.

Methods: 60 obese older adults (65-75 years old) with NAFLD were randomly assigned equally to two groups: a study group and a control group. The study group received LLLT and MD, while the control group followed MD only. These findings evaluated the changes in the level of liver enzymes, serum lipid profile, and anthropometric measurements (body mass index [BMI] and waist circumference [WC]) after 12 weeks of intervention.

Results: Both study and control groups showed a significant reduction in the levels of liver enzymes, serum lipid profile, BMI, and WC $(P<0.001$ and $P<0.01$ respectively); however, the study group showed more significant results compared to the control group $(P<0.01)$.

Conclusion: LLLT and MD may be considered as a treatment approach for NAFLD in older adults to improve their liver function, control dyslipidemia, and help in losing weight.

Keywords: Laser therapy; Liver function; Mediterranean diet; Non-alcoholic fatty liver.
\end{abstract}

\section{Introduction}

Excessive abnormal accumulation of liver fat cells is a common medical condition called fatty liver which refers to the most common form of non-alcoholic fatty liver disease ${ }^{1}$ (NAFLD). A progressive increase in the prevalence of NAFLD was noticed globally as a result of the marked increase in related risk factors including advanced age, ${ }^{2}$ obesity, dyslipidemia, hypertension, and lack of exercise, ${ }^{3}$ with the prevalence exceeding $40 \%$ in older adults ${ }^{4}$ (over 65 years old).

Obesity is closely associated with NAFLD and elevated liver enzymes ${ }^{5}$ like alanine aminotransferase (ALT), aspartate aminotransferase (AST), and alkaline phosphatase (ALP) which are positively correlated to several metabolic syndromes. ${ }^{6}$ The high prevalence of this disease has necessitated searching for an affordable treatment for augmenting disease progression and controlling risk factors.?
Nutritional education, physical activity, and the use of non-pharmacological methods play a critical role in NAFLD management. ${ }^{8}$ Mediterranean diet (MD) is identified to be the most effective diet for the prevention of obesity-related diseases. ${ }^{9,10}$ The beneficial approaches of laser therapy have been approved through providing biochemical reactions on the cellular and molecular levels. $^{11}$

Considerable studies have reported the impact of lowlevel laser therapy (LLLT) as a non-invasive method for body contouring and how it positively reduces cholesterol and triglyceride levels in addition to liver fats. ${ }^{12}$ It has been established that LLLT application together with nutritional education and exercise not only reduce anthropometric parameters, ${ }^{13}$ but also reverse dyslipidemia ${ }^{14}$ and alter hepatic dysfunction. ${ }^{15}$ This study aimed to investigate the effect of LLLT application along with MD on liver function in older adults with NAFLD. 


\section{Materials and Methods \\ Study Design and Sampling}

In a randomized, controlled, parallel, two-groups trial which was conducted and reported according to CONSORT guidelines, 60 NAFLD patients (30 men and 30 women) aged from 65-75 years were recruited from the outpatient clinic of tropical medicine department of Zagazig University hospital (Zagazig, Egypt). The patients were eligible if their criteria were the following: body mass index (BMI) ranging from 30 to $34.9 \mathrm{~kg} /$ $\mathrm{m}^{2}$, having high triglyceride (TG) with low-density lipoprotein (LDL) levels (more than 150 and $130 \mathrm{mg} / \mathrm{dL}$, respectively) in addition to high-risk waist circumference (WC) measurements (men: $102 \mathrm{~cm}$ or more; women: $89 \mathrm{~cm}$ or more), elevated ALT levels on two separate determinations (defined as 20 or more Unites/L U/L and above the normal gender-specific ALT levels: males: ALT $\geq 60 \mathrm{U} / \mathrm{L}$; females: ALT $\geq 50 \mathrm{U} / \mathrm{L}) .{ }^{16}$ Non-smokers, sedentary lifestyle patients (low level of physical activity defined by categorical scoring of International Physical Activity Questionnaire IPAQ $)^{18}$ with fatty liver infiltration confirmed by abdominal ultrasound also included in this study.

However, patients who had a history of cardiovascular disease, an implanted device in the target area for laser light therapy, photosensitivity disorder, current active cancer or within one year of cancer treatment or remission, active infection, wound or other external trauma to the target area to receive laser therapy, excessive alcohol consumption defined as more than 60 $\mathrm{g} / \mathrm{d}$ and patients with evidence of chronic viral hepatitis were excluded. Also excluded patients with cognitive impairment, currently taking lipid-lowering medications or participated in weight loss/exercise program and other types of clinical research in the past 30 days as well.

\section{Randomization}

For randomization in this controlled study, a computergenerated schedule using random permuted blocks was used (1:1 randomization) to ensure an equal number (30 patients) of participants in each group (Figure 1). The treatment codes were stored in sealed envelopes during the study indicating the treatment assignment for the given subject.

\section{Intervention Protocol}

The baseline data of the study participants are summarized in Table 1 including general characteristics of 60 NAFLD patients. Blood sample collection and anthropometric measurements were obtained between 9-11 AM at the baseline and after the study completion (three months). A nutritional assessment, as well as medical and anthropometric examinations, were performed for each patient. Heights and body weights were measured without shoes and heavy clothes for automatic measurement of BMI using digital TR-200 LP (China). For lipid profile and liver enzymes evaluation, a venous blood sample was drawn into a test tube containing anticoagulant (ethylenediaminetetraacetic acid) using the Biochemistry analyzer (India). To measure WC, a tape was used to measure the distance around the smallest part of the waist, just above the abdominal button.

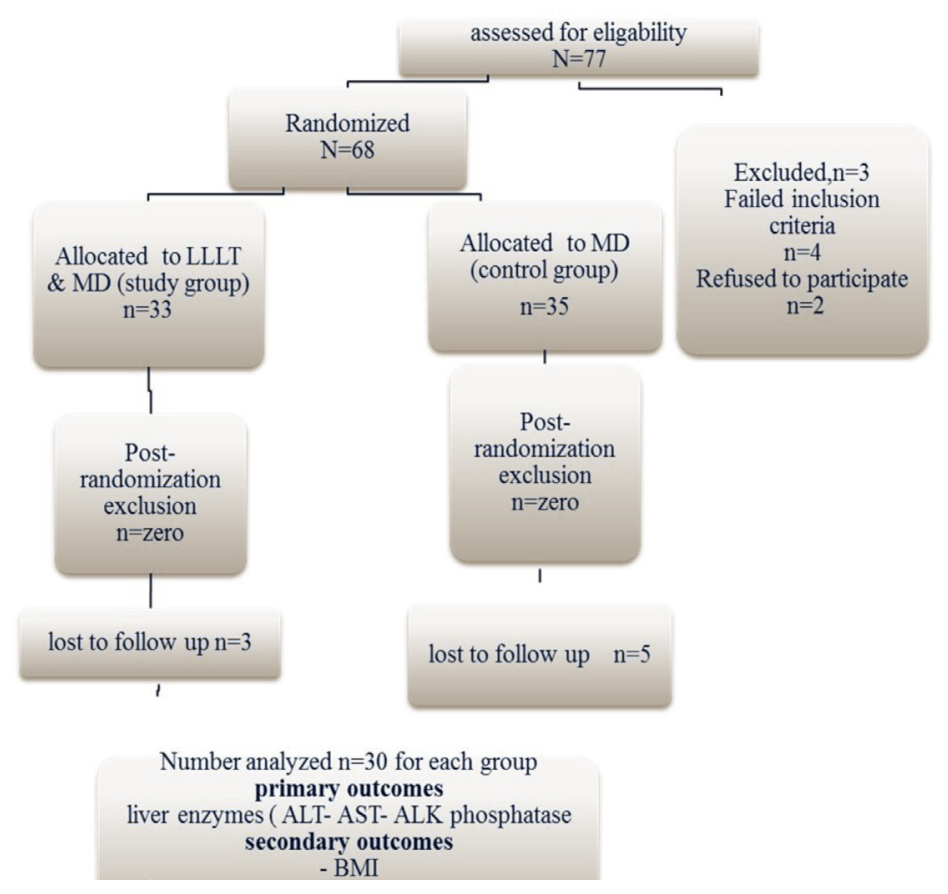

Figure 1. Flow Chart Describing the Study Design and Sample Composition. 
Table 1. Baseline Characteristics of Study Participants

\begin{tabular}{|c|c|c|c|c|c|}
\hline \multicolumn{3}{|c|}{ Characteristics } & \multirow{3}{*}{$\begin{array}{c}\text { Study Group }(\mathbf{n}=\mathbf{3 0}) \\
66.10 \pm 4.56 \\
60.00-75.00\end{array}$} & \multirow{3}{*}{$\begin{array}{c}\text { Control Group }(\mathbf{n}=\mathbf{3 0}) \\
67.12 \pm 5.06 \\
60.00-75.00\end{array}$} & \multirow{3}{*}{$\begin{array}{c}\boldsymbol{P} \text { Value } \\
0.417\end{array}$} \\
\hline \multirow{2}{*}{ Age $(y)$} & & Mean \pm SD & & & \\
\hline & & Range & & & \\
\hline \multirow{2}{*}{ Height (m) } & & Mean \pm SD & $157.85 \pm 5.96$ & $156.11 \pm 6.08$ & \multirow{2}{*}{0.268} \\
\hline & & Range & $148.00-168.00$ & $148.00-167.00$ & \\
\hline \multirow{2}{*}{ Weight (kg) } & & Mean \pm SD & $89.09 \pm 6.80$ & $87.81 \pm 7.60$ & \multirow{2}{*}{0.493} \\
\hline & & Range & $76.60-105.90$ & $76.60-109.40$ & \\
\hline \multirow{2}{*}{$\mathrm{BMI}\left(\mathrm{kg} / \mathrm{m}^{2}\right)$} & & Mean \pm SD & $35.81 \pm 2.80$ & $36.04 \pm 2.51$ & \multirow{2}{*}{0.743} \\
\hline & & Range & $30.60-39.80$ & $30.60-39.70$ & \\
\hline \multirow{4}{*}{ WC (cm) } & \multirow{2}{*}{ Male } & Mean \pm SD & $109.08 \pm 8.43$ & $109.65 \pm 9.27$ & \multirow{2}{*}{0.861} \\
\hline & & Range & $98.00-126.20$ & $97.00-127.00$ & \\
\hline & \multirow{2}{*}{ female } & Mean \pm SD & $99.13 \pm 8.46$ & $100.73 \pm 8.71$ & \multirow{2}{*}{0.612} \\
\hline & & Range & $86.00-115.20$ & $87.00-115.80$ & \\
\hline \multirow{2}{*}{\multicolumn{2}{|c|}{ SGOT-AST (U/L) }} & Mean \pm SD & $50.10 \pm 10.19$ & $47.40 \pm 9.57$ & \multirow{2}{*}{0.294} \\
\hline & & Range & $34.00-66.00$ & $33.00-65.00$ & \\
\hline \multirow{2}{*}{\multicolumn{2}{|c|}{ SGPT-ALT (U/L) }} & Mean \pm SD & $51.63 \pm 9.23$ & $53.43 \pm 9.84$ & \multirow{2}{*}{0.468} \\
\hline & & Range & $37.00-71.00$ & $38.00-70.00$ & \\
\hline \multirow{4}{*}{$\begin{array}{l}\text { ALP } \\
\text { phosphatase } \\
(\mathrm{U} / \mathrm{L})\end{array}$} & \multirow{2}{*}{ Male } & Mean \pm SD & $206.93 \pm 42.78$ & $213.47 \pm 42.57$ & \multirow{2}{*}{0.678} \\
\hline & & Range & $149.00-285.00$ & $151.00-284.00$ & \\
\hline & \multirow{2}{*}{ Female } & Mean \pm SD & $208.20 \pm 26.21$ & $211.67 \pm 23.76$ & \multirow{2}{*}{0.707} \\
\hline & & Range & $165.00-247.00$ & $166.00-250.00$ & \\
\hline \multirow{2}{*}{\multicolumn{2}{|c|}{ Total cholesterol (mg/dL) }} & Mean \pm SD & $215.97 \pm 14.42$ & $219.00 \pm 13.92$ & \multirow{2}{*}{0.410} \\
\hline & & Range & $190.00-242.00$ & $191.00-243.00$ & \\
\hline & Male & Mean \pm SD & $36.00 \pm 4.71$ & $35.80 \pm 5.65$ & 017 \\
\hline וمוH & 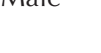 & Range & $28.00-44.00$ & $27.00-43.00$ & 0.917 \\
\hline IIIL (II & Comb & Mean \pm SD & $45.33 \pm 5.60$ & $44.80 \pm 5.82$ & ת \\
\hline & 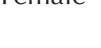 & Range & $37.00-55.00$ & $36.00-54.00$ & 0.000 \\
\hline Imo/dl) & & Mean \pm SD & $146.07 \pm 11.44$ & $143.57 \pm 12.70$ & \\
\hline LEL (IIIS UL) & & Range & $126.00-166.00$ & $125.00-165.00$ & 0.720 \\
\hline & & Mean \pm SD & $154.37 \pm 23.44$ & $153.77 \pm 23.59$ & \\
\hline (U) (Img/uL) & & Range & 108.00-195.00 & $107.00-194.00$ & 0.922 \\
\hline & Male & Mean \pm SD & $5.59 \pm 0.69$ & $5.63 \pm 0.65$ & 0.887 \\
\hline T. CHOL / & & Range & $4.70-6.60$ & $4.60-6.50$ & \\
\hline HDL & Female & Mean \pm SD & $4.56 \pm 0.62$ & $4.65 \pm 0.71$ & 0725 \\
\hline & & Range & $3.70-5.80$ & $3.60-5.70$ & 0.123 \\
\hline & Mal & Mean \pm SD & $4.01 \pm 0.38$ & $3.84 \pm 0.37$ & 221 \\
\hline & Tivate & Range & $3.45-4.65$ & $3.50-4.60$ & 0.221 \\
\hline & & Mean \pm SD & $3.56 \pm 0.33$ & $3.60 \pm 0.34$ & \\
\hline & rem & Range & $3.03-4.22$ & $3.01-4.20$ & 0.742 \\
\hline
\end{tabular}

ALP phosphatase: Alkaline Phosphatase, BMI: body mass index, HDL: high-density lipoprotein, LDL: low-density lipoprotein, T. CHOL: total cholesterol, TG: triglyceride, SGOT-AST: serum aspartate aminotransferase, SGPT-ALT: serum alanine aminotransferase.

Data represented as mean \pm standard deviation (SD).

*Statistically significant at $\mathrm{P} \leq 0.05$ according to independent samples $t$ test. 


\section{Low-Level Laser Application}

The laser therapy device $(660 \mathrm{~nm})$ which consisted of abdominal straps containing 4 LED clusters (having 72 LEDs each) was applied in the study group around the patients' abdomen and waist after cleaning the target area and wearing safety goggles ${ }^{19}$ for 30 minutes. This procedure was performed two times per week over 12 weeks with specific parameters listed in Table 2.

\section{Diet Prescription}

The recommended composition of MD regimen according to $\mathrm{Be}^{\prime}$ dard et $\mathrm{al}^{20}$ was as follows: increasing the consumption of virgin olive oil (302 mL/wk), one bread piece or $30 \mathrm{~g}$ cereal, serving size for whole-grain products (125 mL) (rice, pasta, bulgur, and couscous), serving size for eggs (100 g), serving size for fruits and vegetables (125 $\mathrm{mL})$, and serving size for legumes $(175 \mathrm{~mL})$ and nuts $(30$ g). In addition, the patients were encouraged to consume serving size for fish and poultry (75 g), with one weekly serving of red meat and serving size for low-fat dairy products (50 g cheese, $175 \mathrm{~g}$ yoghurt, and $250 \mathrm{~mL}$ milk). So, the diet plan included generally $50 \%$ carbohydrates (from vegetables, fruits, legumes, and whole grains), 35\% fats (from healthy oils, nuts, seeds, and fish), and 15\% protein (from legumes, fish, nuts, dairy, poultry, and eggs).

In our study, a restriction of approximately $15 \%$ kilocalories was recommended based on the total daily requirement and the level of activity $(2000 \mathrm{kcal} / \mathrm{d}$ for men and $1600 \mathrm{kcal}$ for women ${ }^{21,22}$ ). Nutritional guidance

Table 2. Laser Therapy Parameters Applied in This Study

\begin{tabular}{|c|c|}
\hline Parameters & \\
\hline Wavelength (nm) & 660 \\
\hline Spectral width (nm) & 20 \\
\hline Operating mode & Continuous \\
\hline Application technique & Contact \\
\hline $\begin{array}{l}\text { Average radiant power-one LED } \\
(\mathrm{mW})\end{array}$ & 5 \\
\hline Aperture diameter-one LED $(\mathrm{cm})$ & 0.3 \\
\hline Power density (mW/cm2) & 71 \\
\hline $\begin{array}{l}\text { Beam spot size at target- one LED } \\
\left(\mathrm{cm}^{2}\right)\end{array}$ & 0.071 \\
\hline Total number of LEDs & 288 \\
\hline Area irradiated $(\mathrm{cm} 2)$ & 20.4 \\
\hline Irradiance at target $\left(\mathrm{mW} / \mathrm{cm}^{2}\right)$ & 71 \\
\hline Radiant exposure (J/cm2) & 127.8 \\
\hline Energy density at aperture $\left(\mathrm{J} / \mathrm{cm}^{2}\right)$ & 127.8 \\
\hline Radiant energy (kJ) & 2.6 \\
\hline Application & $\begin{array}{l}30 \text { min, } 2 \text { times per } \\
\text { week over } 12 \text { weeks }\end{array}$ \\
\hline
\end{tabular}

was provided during the study period to evaluate diet adherence through bi-weekly sessions with a dietitian. All participants were instructed and trained to use 24-hour recall dietary assessment of food composition which was evaluated in every nutritional session.

\section{Sample Size Calculation}

The sample size was determined prior to the study using $\mathrm{G}^{\star}$ Power statistical software (version 3.1.9.2; Franz Faul, Universitat Kiel, Germany) [ $t$ tests-Means: Difference between two independent means (two groups), based on the $d$ (effect size) of 0.73 , $\alpha$ error $=0.05,1-\beta$ error $=0.8$ revealed that, the appropriate required sample size for the study was 60].

\section{Statistical analysis}

Statistical analysis was performed with SPSS statistical software, version 25. The Shapiro-Wilk test was used to determine whether the data were distributed normally or not. Continuous data were described as mean \pm standard deviation (SD). Baseline characteristics between the two groups were compared using the independent samples $t$ test. Both dependent and independent samples $t$ tests were used to investigate the changes in variables before and after the intervention, as well as the differences between the experimental and control groups respectively. $P$ values less than or equal to 0.05 were considered statistically significant.

\section{Results}

Sixty NAFLD patients consented to participate in the current study, and they were randomly assigned to two groups (30 patients per group). The mean age of all participants was $66.61 \pm 4.80$ years with mean weight and BMI of $88.45 \pm 7.18 \mathrm{~kg}$ and $35.95 \pm 2.64 \mathrm{~kg} / \mathrm{m}^{2}$ respectively. Thirty patients received LLLT along with MD (study group) and the other 30 patients served as the control group followed only the same diet regimen. For each analysis, the differences between the baseline and postintervention were calculated and reported showed no statistically significant differences between-groups in baseline parameters, age, height, weight, BMI, WC and liver function (SGOT-AST, SGPT-ALT, ALP phosphatase) as well as lipid profile levels (Total cholesterol, LDL, HDL, TG, T. CHOL/HDL and LDL-C/HDL $)(P$ value $>0.05)$ (Table 1).

By the end of the study, statistically significant differences in BMI, WC, serum liver enzymes (SGOTAST, SGPT-ALT, ALP phosphatase) (Table 3) and lipid profile levels (total cholesterol, LDL, HDL, TG, T. CHOL /HDL, and LDL-C/HDL) between the pre- and postintervention either in the study group or control group were noted (Table 4 ).

\section{Anthropometric Measures and Liver Serum Enzymes}


Table 3. Comparison of BMI, WC and Liver Enzymes Concentration Before and After the Intervention (12 Weeks)

\begin{tabular}{|c|c|c|c|c|c|c|c|c|}
\hline \multicolumn{2}{|c|}{ Variable } & \multicolumn{2}{|c|}{$\begin{array}{l}\text { Study Group } \\
\quad(n=30)\end{array}$} & \multirow[t]{2}{*}{$P$ Value $^{\mathrm{a}}$} & \multicolumn{2}{|c|}{$\begin{array}{l}\text { Control Group } \\
\qquad(\mathrm{n}=30)\end{array}$} & \multirow[t]{2}{*}{$P$ Value $^{\mathrm{a}}$} & \multirow[t]{2}{*}{$P$ Value $^{\mathrm{b}}$} \\
\hline & & Before & After & & Before & After & & \\
\hline \multicolumn{2}{|l|}{ BMI $\left(\mathrm{kg} / \mathrm{m}^{2}\right)$} & $35.81 \pm 2.80$ & $31.98 \pm 2.67$ & $0.001^{*}$ & $36.04 \pm 2.51$ & $33.86 \pm 2.4$ & $0.01^{*}$ & $0.01^{* *}$ \\
\hline \multirow{2}{*}{ WC $(\mathrm{cm})$} & Male & $109.08 \pm 8.43$ & $94.00 \pm 8.11$ & $0.001^{*}$ & $109.65 \pm 9.27$ & $103.01 \pm 9.12$ & $0.01^{*}$ & $0.01^{* *}$ \\
\hline & Female & $99.13 \pm 8.46$ & $84.55 \pm 8.63$ & $0.001^{*}$ & $100.73 \pm 8.71$ & $93.89 \pm 8.34$ & $0.01^{*}$ & $0.01^{* *}$ \\
\hline \multicolumn{2}{|l|}{ SGOT-AST (U/L) } & $50.10 \pm 10.19$ & $33.10 \pm 8.11$ & $0.001^{*}$ & $47.40 \pm 9.57$ & $40.07 \pm 9.26$ & $0.01^{*}$ & $0.01^{* *}$ \\
\hline \multicolumn{2}{|l|}{ SGPT-ALT (U/L) } & $51.63 \pm 9.23$ & $32.70 \pm 6.82$ & $0.001^{*}$ & $53.43 \pm 9.84$ & $45.00 \pm 9.05$ & $0.01^{*}$ & $0.01^{* *}$ \\
\hline \multirow{2}{*}{$\begin{array}{l}\text { ALP phosphatase } \\
(\mathrm{U} / \mathrm{L})\end{array}$} & Male & $206.93 \pm 42.78$ & $168.07 \pm 41.88$ & $0.001^{*}$ & $213.47 \pm 42.57$ & $200.13 \pm 41.39$ & $0.01^{*}$ & $0.01^{* *}$ \\
\hline & Female & $208.20 \pm 26.21$ & $179.53 \pm 25.75$ & $0.001^{*}$ & $211.67 \pm 23.76$ & $199.00 \pm 23.02$ & $0.01^{*}$ & $0.01^{* *}$ \\
\hline
\end{tabular}

ALP phosphatase: Alkaline Phosphatase BMI: Body mass index. SGOT-AST: Serum Aspartate Aminotransferase. SGPT-ALT: Serum Alanine Aminotransferase. Data represented as mean \pm standard deviation (SD).

a Paired $t$ test; ${ }^{\mathrm{b}}$ Independent $t$ test.

* Statistically significant at $P \leq 0.05$ according to paired samples $t$ test.

**Statistically significant at $P \leq 0.05$ according to independent samples $t$ test.

Table 4. Comparison of Lipid Profile Components Before and After the Intervention (12 Weeks)

\begin{tabular}{|c|c|c|c|c|c|c|c|c|}
\hline \multirow{2}{*}{\multicolumn{2}{|c|}{ Variable }} & \multicolumn{2}{|c|}{$\begin{array}{c}\text { Study Group } \\
(n=30)\end{array}$} & \multirow{2}{*}{$P$ Value $^{\mathrm{a}}$} & \multicolumn{2}{|c|}{$\begin{array}{c}\text { Control Group } \\
(n=30)\end{array}$} & \multirow{2}{*}{$P$ Value $^{\mathrm{a}}$} & \multirow{2}{*}{$P$ Value $^{b}$} \\
\hline & & Before & After & & Before & After & & \\
\hline Total cholestero & (mg/dL) & $215.97 \pm 14.42$ & $187.60 \pm 13.81$ & $0.001^{*}$ & $219.00 \pm 13.92$ & $206.00 \pm 13.44$ & $0.01 *$ & $0.01^{* *}$ \\
\hline \multirow{2}{*}{$\mathrm{HDL}(\mathrm{mg} / \mathrm{dL})$} & Male & $36.00 \pm 4.71$ & $41.33 \pm 4.60$ & $0.001^{*}$ & $35.80 \pm 5.65$ & $37.53 \pm 5.50$ & $0.01^{*}$ & $0.01^{* *}$ \\
\hline & Female & $45.33 \pm 5.60$ & $50.60 \pm 5.54$ & $0.001^{*}$ & $44.80 \pm 5.82$ & $46.27 \pm 5.52$ & $0.01^{*}$ & $0.01^{* *}$ \\
\hline $\mathrm{LDL}(\mathrm{mg} / \mathrm{dL})$ & & $146.07 \pm 11.44$ & $126.33 \pm 10.51$ & $0.001^{*}$ & $143.57 \pm 12.70$ & $135.13 \pm 12.90$ & $0.01^{*}$ & $0.01^{* *}$ \\
\hline $\mathrm{TG}(\mathrm{mg} / \mathrm{dL})$ & & $154.37 \pm 23.44$ & $125.17 \pm 22.20$ & $0.001^{*}$ & $153.77 \pm 23.59$ & $142.23 \pm 23.13$ & $0.01^{*}$ & $0.01^{* *}$ \\
\hline \multirow{2}{*}{ T. CHOL / HDL } & Male & $5.59 \pm 0.69$ & $3.51 \pm 0.59$ & $0.001^{*}$ & $5.63 \pm .65$ & $4.75 \pm 0.70$ & $0.01^{*}$ & $0.01^{* *}$ \\
\hline & Female & $4.56 \pm 0.62$ & $2.63 \pm 0.62$ & $0.001^{*}$ & $4.65 \pm 0.71$ & $3.85 \pm 0.67$ & $0.01^{*}$ & $0.01^{* *}$ \\
\hline \multirow{2}{*}{ LDL-C/HDL } & Male & $4.01 \pm 0.38$ & $2.10 \pm 0.42$ & $0.001^{*}$ & $3.84 \pm .37$ & $3.03 \pm 0.37$ & $0.01^{*}$ & $0.01^{* *}$ \\
\hline & Female & $3.56 \pm 0.33$ & $1.62 \pm 0.34$ & $0.001^{*}$ & $3.60 \pm .34$ & $2.82 \pm 0.29$ & $0.01^{*}$ & $0.01^{* *}$ \\
\hline
\end{tabular}

HDL: High-density lipoprotein, LDL: low-density lipoprotein, T. CHOL: total cholesterol, TG: triglyceride.

Data represented as mean \pm standard deviation (SD).

a Paired $t$ test; ${ }^{\mathrm{b}}$ Independent $t$ test.

* Statistically significant at $P \leq 0.05$ according to paired samples $t$ test.

** Statistically significant at $P \leq 0.05$ according to independent samples $t$ test.

By the end of the study, a statistically significant reduction of BMI, WC and serum liver enzymes (SGOT-AST, SGPT-ALT, ALP phosphatase) was observed in the study group $(P<0.001)$ and the control group $(P<0.01)$. The difference between the groups showed more significant results in the study group compared to the control group. SGOT-AST $(\mathrm{u} / \mathrm{L})$ and SGPT-ALT $(\mathrm{u} / \mathrm{L})$ concentrations were significantly lower in obese fatty liver patients in the study group ( $33.10 \pm 8.11$ and $32.70 \pm 6.82 \mathrm{u} / \mathrm{L}$ respectively) than the control group $(40.07 \pm 9.26$ and $45.00 \pm 9.05 \mathrm{u} / \mathrm{L}$ respectively) $(P<0.01)$, as shown in Table 3 .

\section{Lipid Profile}

Table 4 provides the estimated between-group differences over time concerning lipid profile levels. There was a significant increase in HDL $(\mathrm{mg} / \mathrm{dL})$ concentration in both obese male and female patients after the intervention in the study group, compared to the control group after 12 weeks $(P<0.01)$. The T. CHOL/HDL ratio showed a statistically significant reduction between the study and control groups after 12 weeks of follow-up. Also, it was observed that LLLT had an improving effect on the LDL-C/HDL ratio compared to the control group $(P<$ $0.01)$

\section{Discussion}

Based on the high prevalence of health risks threatening obese older adults, this study was conducted to highlight the effect of LLLT application along with MD as a noninvasive and alternative approach with no or minimal side effects on liver function in obese older adults with NAFLD. In the current study, we evaluated the impact of LLLT and MD on older adults (65-75 years old) with NAFLD and how this approach affected the levels of liver enzymes, lipid profile, BMI, and WC.

The results at the end of the intervention indicated that the application of LLLT two times per week for 12 weeks in addition to following the MD plan (study group) 
was better than following MD only (control group) in improving liver function and lipid profile as well as losing weight in older adults with NAFLD. A significant reduction in the levels of liver enzymes (ALT, AST, ALP phosphate), lipid profile (T.C, T.G, LDL), BMI, and WC compared to the baseline values was noted. In addition, a significant increase was observed in the HDL levels within the groups, with the study group showing better results.

All participants experienced no side effects and expressed high satisfaction during the study period. In addition to the safe application of LLLT with positive results, MD not only enhanced weight loss, but also had a positive impact on cardiometabolic risk factors with easy long-term plan adherence.

Consistent with previous studies, the application of LLLT two times per week was highly effective in the reduction of weight and body fat mass. ${ }^{23}$ These findings are also confirmed by Jackson et $\mathrm{al}^{24}$ in a placebocontrolled study in which the bi-weekly LLLT treatments for overweight participants resulted in losing a total of 3.0 inches and more from the waist, hip, and bilateral thighs from the baseline to the end of treatment in the active LLLT group compared to the sham LLLT group. In our study, a significant reduction of WC was observed at the end of the intervention compared to the baseline, which was supported by McRae and Boris ${ }^{25}$ retrospective studies in which a concomitant decrease was reported in weight and body measurements (waist, hips and thighs) after LLLT application.

Thus, LLLT can also improve lipid metabolism and control dyslipidemia-related diseases. ${ }^{26}$ In the pilot clinical study of Jackson et al, ${ }^{27}$ the investigators reported the effect of LLLT $(635 \mathrm{~nm})$ on lipid parameters and reported a significant reduction in T.G and cholesterol levels after two weeks of application (three sessions per week). Pelkman et $\mathrm{al}^{28}$ found that MD with moderate consumption of monounsaturated fat exhibited a promising effect on the serum lipid profile in obese people. Gepner et $\mathrm{al}^{29}$ concluded that MD (low carbohydrates) was more effective than a low-fat diet in reducing the percentage of hepatic fat content independently of visceral adipose tissue loss, with more beneficial effects on specific cardiometabolic parameters.

Concerning the MD effect on liver function, in a systematic review which included ten randomized controlled trials, Moosavian et $\mathrm{al}^{30}$ demonstrated that MD may improve NAFLD severity, anthropometric measures, lipid profile, liver enzymes, and glycemic indices among patients with NAFLD, which is compatible with our findings.

Despite the positive outcomes in our study, we noted some limitations. The expected differences between males and females in either laboratory or anthropometric measures were not statistically justified or fully explained. In addition, the adherence to MD in this study was assessed only by a questionnaire and the diet session attendance. Also, the improvement in liver function and inflammation was traced only by laboratory parameters. Histological tissue analysis or magnetic resonance imaging would increase the accuracy to quantify our outcomes. Finally, it may be difficult to extend conclusions to patients with more advanced liver disease. Further researches are recommended to cover this shortage. Moreover, the novelty of this kind of intervention along with the noted effective benefits suggests that LLLT application combined with MD plays a remarkable role in improving liver function rather than focusing on weight loss only. Thus, we could say that this safe intervention can be used as a specific new approach for NAFLD patients.

\section{Conclusion}

The overall results of our study suggest that LLLT and MD can be a valuable tools in improving NAFLD by controlling the related metabolic risks as obesity, hyperlipidemia and elevated liver enzymes. Indeed, both LLLT and MD may be considered as healthy and effective implements in obese older adults with NAFLD.

\section{Authors' Contribution}

EN contributed to the conception or design of the work. FM contributed to the acquisition of data. MM contributed to analysis and interpretation of data for the work. AJ drafted the manuscript. EN, FM and MM critically revised the manuscript. All gave final approval and agree to be accountable for all aspects of work ensuring integrity and accuracy.

\section{Conflict of Interests}

No potential conflict of interest was reported by the author.

\section{Ethical Approval}

Written informed consent was taken from each participant. The trial protocol was treated according to the principles of the Declaration of Helsinki and approved by Faculty of Physical Therapy Ethics Committee for Scientific Research (P.T.REC/012/002722). Additionally, this study was registered at www.ClinicalTrials.gov (identifier: NCT04452409)

\section{Funding}

The authors received no financial support for the research and publication of this article.

\section{Acknowledgement}

The authors thank Ebthall Mohamed for her assistance in data analysis and interpretation. We would like to thank all participants who consented to join in this study.

\section{References}

1. Angulo P. Non alcoholic fatty liver disease. $N$ Engl J Med. 2002; 346:1221-31. doi: 10.1056/NEJMra011775

2. Mahmoud HS, Helal MM, Hassan MH, Sherif MF. Correlation between anthropometric measures, lipid profile and serum adiponectin and steatosis in nondiabetic nonalcoholic fatty liver disease. $\mathrm{Br} J$ Med Med Res. 2015; 7:771-778. doi: 10.9734/BJMMR/2015/16594

3. Mohamed AA, Gohary KK, Mashad GM, Hammoda GE, Abdallah AM, Khattab RA. et al. Interleukin 10, thyroid status and ferritin are non-invasive prognostic biomarkers 
for diagnosis of fatty liver disease in children. J Int Res Med Pharm Sci. 2016; 8:85-93.

4. Maher JJ, Leon P, Ryan JC. Beyond insulin resistance: Innate immunity in nonalcoholic steatohepatitis. Hepatology. 2008; 48:670-678. doi: 10.1002/hep.22399

5. Esteghamati A., Jamali A., Khalilzadeh O., Noshad S., Khalili M., Zandieh A.,et al.. Metabolic syndrome is linked to a mild elevation in liver aminotransferases in diabetic patients with undetectable non-alcoholic fatty liver disease by ultrasound. Diabetol Metab Syndr. 2010; 2:65. https:// doi.org/10.1186/s13098-020-00570-y.

6. Koga M, Saito H, Mukai M, Saibara T, Kasayama S. Serum dehydroepiandrosteronesulphate levels in patients with non-alcoholic fatty liver disease. Intern Med. 2011; 50:1657-1661.

7. Donnelly JE, Blair SN, Jakicic JM, Manore MM, Rankin JW, Smith BK. Appropriate physical activity intervention strategies for weight loss and prevention of weight regain for adults. Med Sci Sports Exerc .2009; 41: 459-471. doi: 10.1249/MSS.0b013e3181949333

8. Chin SH, Kahathuduwa CN, Binks M. Physical activity and obesity: What we know and what we need to know. Obes Rev. 2016;1226-1244. doi:10.1111/obr.12460.

9. Romagnolo DF, Selmin OI. Mediterranean Diet and Prevention of Chronic Diseases. Nutr Today. 2017; 52: 208222. doi: 10.1016/j.semcancer.2017.06.011

10. Sofi F, Abbate R, Gensini GF, Casini A . Accruing evidence on benefits of adherence to the Mediterranean diet on health: An updated systematic review and meta-analysis. Am J Clin Nutr. 2010;92: 1189-1196. doi: 10.1136/bmj. a1344

11. Marventano S, Kolacz P, Castellano S, Galvano F, Buscemi S, Mistretta A, Grosso G. Areviewofrecent evidence in human studies of $n-3$ and n-6 PUFA intake on cardiovascular diseases, cancer, and depressive disorders: Does the ratio really matter? Int J Food Sci Nutr. 2015. doi: 10.3109/09637486.2015.1077790

12. Rosenbaum M, Prieto V, Hellmer J, Boschmann M, Krueger J, Leibel RL et al. An exploratory investigation of the morphology and biochemistry of cellulite. Plast Reconstr Surg. 1998;101(7):1934-1939. doi: 10.1097/00006534199806000-00025.

13. Nestor MS, Newburger J, Zarraga MB. Body contouring using 635-nm low level laser therapy. Semin Cutan Med Surg. 2013;32(1):35-40.

14. Jackson FR, Roche GC, Wisler K. Reduction in cholesterol and triglyceride serum levels following low-level laser irradiation: A noncontrolled, nonrandomized pilot study. Am J Cosmet Surg. 2010;27(4):177-184. 35.

15. Aquino AE Jr, Sene-Fiorese M, Paolillo FR, Duarte FO, Oishi JC, Pena AA et al. Low-level laser therapy (LLLT) combined with swimming training improved the lipid profile in rats fed with high-fat diet. Lasers Med Sci. 2013; 28: 1271-1280. doi: 10.1007/s10103-012-1223-Z.

16. Sanyal, D. Mukherjee, P., Raychaudhuri, M., Ghosh,S., Mukherjee.S. \& Chowdhury,S . Profile of liver enzymes in non-alcoholic fatty liver disease in patients with impaired glucose tolerance and newly detected untreated type 2 diabetes. Indian J Endocrinol Metab. 2015; 19(5): 597-601. .doi: 10.4103/2230-8210.163172.

17. Hegazy M, Mostafa A. Liver Ultrasound
Scanning in the Detection of Hepatic Steatosis and Fibrosis in NASH Patients. Egypt J Intern Med. 2012; 24 27-31. doi: 10.7123/01. EJIM.0000419544.37462.5f

18. Mader U, Martin BW, Schutz Y, Marti B. "Validity of four short physical activity questionnaires in middle-aged persons." Med Sci Sports Exerc. 2006; 38: 1255-66. doi: 10.1249/01.mss.0000227310.18902.28.

19. Croghan IT, Hurt RT, Schroeder DR, , Fokken SC, Jensen $\mathrm{MD}$, Clark MM et al, Low-level laser therapy for weight reduction: a randomized pilot study. Laser Med Sci 2020;35:663-75. doi: 10.1007/s10103-019-02867-5

20. Be'dard A, Riverin M, Dodin S, Corneau L, Lemieux S. Sex differences in the impact of the Mediterranean diet on cardiovascular risk profile. Br J Nutr. 2012; 108: 1428-1434. doi: 10.1017/S0007114511006969.

21. Lichtenstein AH, Rasmussen $\mathrm{H}, \mathrm{Yu}$ WW, Epstein SR, Russell R M “Modified MyPyramid for Older Adults." J Nutr. 2008; 138: 1 5-11. doi: 10.1093/jn/138.1.5.

22. Harris JA, Benedict FG. A Biometric Study of Human Basal Metabolism. Natl Acad Sci U S A. 1918. 4 (12): 370-373. doi: 10.1073/pnas.4.12.370

23. Avci P, Nyame TT, Gupta GK, Sadasivam M, Hamblin MR. Low-level laser therapy for fat layer reduction: a comprehensive review. Lasers Surg Med. 2013; 45(6):349357. doi: 10.1002/lsm.22153

24. Jackson RF, Roche GC, Shanks SC. A double-blind, placebo-controlled randomized trial evaluating the ability of low-level laser therapy to improve the appearance of cellulite. Lasers Surg Med. 2013; 45(3):141-147. doi: 10.1002/lsm.22119.

25. McRae E, Boris J. Independent evaluation of low-level laser therapy at $635 \mathrm{~nm}$ for non-invasive body contouring of the waist, hips, and thighs. Lasers Surg Med. 2013;45(1):1-7. doi: 10.1002/lsm.22113.

26. Caruso-Davis MK, Guillot TS, Podichetty VK, Mashtalir N, Dhurandhar NV, Dubuisson O et al. Efficacy of low-level laser therapy for body contouring and spot fat reduction. Obes Surg. 2011; 21(6):722-729. doi: 10.1007/s11695-0100126-y.

27. Jackson RF, Stern FA, Neira R, Ortiz-Neira CL, Maloney J. Application of low-level laser therapy for noninvasive body contouring. Lasers Surg Med. 2012; 44(3):211-217. doi: 10.1002/lsm.22007.

28. Pelkman CL, Fishell VK, Maddox DH, Pearson TA, Mauger DT, Kris-Etherton PM. Effects of moderatefat (from monounsaturated fat) and low-fat weight-loss diets on the serum lipid profile in overweight and obese men and women. Am J ClinNutr. 2004;79(2):204-12. doi: 10.1002/lsm.22007.

29. Gepner Y, Shelef I, Komy O, Cohen N, Schwarzfuchs D, Bril $\mathrm{N}$ et al. The beneficial effects of Mediterranean diet over low-fat diet may be mediated by decreasing hepatic fat content, J Hepatol. 2019;71(2):379-388. doi: 10.1016/j. jhep.2019.04.013.

30. Moosavian S, Arab A, Paknahad Z. The effect of a Mediterranean diet on metabolic parameters in patients with non-alcoholic fatty liver disease: A systematic review of randomized controlled trials. Clin Nutr ESPEN. 2020;35:40-46. doi:10.1016/j.clnesp.2019.10.008 